\title{
Endocrine responses to the oral ingestion of a physiological dose of essential amino acids in humans
}

\author{
M Gröschl, I Knerr, H-G Topf, P Schmid, W Rascher and M Rauh \\ Department of Paediatrics, Friedrich-Alexander-Universität Erlangen-Nuremberg, Germany \\ (Requests for offprints should be addressed to M Gröschl, Klinik für Kinder und Jugendliche, Loschgestrasse 15, 91054 Erlangen, Germany; \\ Email: michael.groeschl@kinder.imed.uni-erlangen.de)
}

\begin{abstract}
The response of insulin, human growth hormone $(\mathrm{hGH})$, cortisol, leptin and ghrelin, in addition to various metabolic parameters, was measured at 10 minute intervals following the oral ingestion of a standardised physiological dose of essential amino acids (AA). Twenty-eight healthy male, fasted volunteers (aged 18-40 yrs, BMI 18.0$24.5 \mathrm{~kg} / \mathrm{m}^{2}$ ) took part in the study; 13 volunteers in the AA group, nine subjects in an iso-caloric control group, and a further six subjects served as fasting controls.

Twenty minutes after ingestion, insulin reached peak concentrations that were up to $500 \%$ higher than basal values $(P<0 \cdot 0001)$. The AA group and iso-caloric control group showed a similar insulin response.

AA ingestion led to an increase in hGH secretion with maximum concentrations being $2100 \pm 1013 \%$ higher than the basal values $(P<0 \cdot 0001)$. In contrast, no changes in hGH concentrations were observed in the iso-caloric controls; in the fasting controls only a slight
\end{abstract}

increase in hGH was found towards the end of the fasting period.

While cortisol decreased significantly $(P<0 \cdot 01)$ during the study in the AA group, neither control group showed a significant change in this parameter.

Changes in leptin levels remained insignificant in all three groups, whereas ghrelin showed a different profile in each of the three groups, i.e. a continuous rise towards the end of the study period $(P<0 \cdot 001)$ in the AA group, a less significant effect for the fasting group, and no effect at all in the iso-caloric control group.

There was no significant correlation between the concentrations or the area under curve of the hormones measured in any of the groups.

The endocrine data provided in this study indicate that a single bolus of essential AA in fasted individuals is associated with both anabolic and catabolic hormonal responses. Journal of Endocrinology (2003) 179, 237-244

\section{Introduction}

Metabolism is the continuous balance of anabolic and catabolic processes enabling the organism to adapt to physiological needs. Whereas carbohydrates and fatty acids are used preferentially as metabolic fuels, the uptake of amino acids (AA) is a prerequisite for anabolism, as in protein synthesis and growth.

In metabolic disorders such as phenylketonuria or maple syrup disease, patients lack particular enzymes to further metabolise one or more essential AA. These patients are given special diets, restricting the intake of these AA, and are supplemented with all the other AA (Dashman \& Sansaricq 1993, Levy 1989). Another, non-clinical, application of AA supplementation was developed for an increasing number of sporting requirements, mainly in order to gain muscle growth (Rubinstein \& Federman 2000, Chromiak \& Antonio 2002).

The aim of our study was to investigate the influence of a standardised AA ingestion on the endocrine parameters involved in metabolic processes. Some hormones, such as insulin (Santora et al. 1979, Fukagawa et al. 1986, Liao \& Lane 1995) and growth hormone (hGH) (Copeland \& Nair 1994), are known to mediate AA uptake in peripheral tissues, whereas catabolic hormones such as the glucocorticoids act by stimulating the enzymes of gluconeogenesis (Tayek \& Katz 1997, Khani \& Tayek 2001). The uptake of AA leads to a further synthesis of androgens (Kingston et al. 1986, Nagata et al. 1999) which additionally support protein synthesis and muscle growth.

We were therefore interested in the extent to which certain hormones, i.e. insulin, cortisol, hGH, leptin and ghrelin, are influenced by the uptake of a standardised physiological AA dosage in a homogenous group of healthy volunteers.

The hypothesis was that AA cause a shift towards anabolic processes which is initiated by increased insulin (Fukagawa et al. 1986, Tessari 1994) and hGH, and accompanied by a decrease in glucocorticoids (Louard et al. 1994). The effect of a single AA bolus on leptin and ghrelin was of particular interest, as kinetic data on the effects of special diets on these two peptide hormones are 
either controversial (Drewes et al. 1997, de Precigout et al. 2000) or completely lacking. In continuation and extension of a promising pilot study we describe hormonal changes as anabolic or catabolic, with two different control groups being involved. One group ingested an iso-caloric drink, the other remained fasted. Finally, based on the findings of our study, and on data from the literature, we sought to develop a model of endocrine responses to oral AA ingestion in healthy subjects.

\section{Materials and Methods}

\section{Subjects, $A A$ dose, and sample preparation}

Twenty-eight healthy male adults (aged 18-40 yrs, BMI $18 \cdot 0-24.5 \mathrm{~kg} / \mathrm{m}^{2}$ ) participated in the study. The proposed study was fully explained to each subject and informed consent was obtained in advance. The protocol was approved by the local ethics committee.

All subjects reported to our laboratory at $0800 \mathrm{~h}$ having fasted for 10-12 h. A permanent catheter (Vasocan, Braun, Melsungen, Germany) was inserted into an antecubital vein and the first blood sample was collected to obtain basal values. Immediately thereafter, 13 volunteers ingested the test mixture of essential AA (SHS International, Heilbronn, Germany) together with $200 \mathrm{ml}$ water within $1 \mathrm{~min}$. Mean load consisted of $24 \mathrm{~g}$ AA mixture (Val, Leu, Ile, Phe, Tyr, Try, Lys, Met, Cys, Thr, His, minerals, trace elements and vitamins), normalised to $0.35 \mathrm{~g}$ AA per $\mathrm{kg}$ body weight. Fifteen subjects served as controls without AA uptake, nine ingested an iso-caloric, skimmed milk powder solution (Naturaflor, Töpfer, Dietmannsried, Germany), containing (per $100 \mathrm{~g}$ powder) $36 \mathrm{~g}$ protein, $52 \mathrm{~g}$ carbohydrates and $1 \mathrm{~g}$ fat. The last six controls remained fasted during the entire study.

During the test, volunteers were rested and allowed to drink water ad libitum. No adverse effects, such as gastrointestinal discomfort, were observed after ingestion of the test powder.

Blood samples were drawn at 10 min intervals until the end of the experiment $\left(t_{\text {end }}=300 \mathrm{~min}\right)$, with the exception of the fasting controls, where intervals of $30 \mathrm{~min}$ were chosen.

Blood was collected in sterile tubes without anticoagulants. After clotting $(10 \mathrm{~min})$, the tubes were centrifuged at $1000 \mathrm{~g}$ for $5 \mathrm{~min}$ at room temperature and serum aliquots were kept frozen at $-80{ }^{\circ} \mathrm{C}$ until analysis.

\section{Analysis of $A A$, glucose, and free fatty acids}

AA measurement was carried out on an LC-3000 analyser (Eppendorf, Hamburg, Germany) after deproteinisation with 5-sulfosalicylic acid. Free fatty acids (FFA) were analysed enzymatically (Wako, Neuss, Germany) using a Hitachi 904 (Roche, Mannheim, Germany). For glucose analysis membrane-bound glucose oxidase was used (Care diagnostica, Voerde, Germany).

\section{Hormone measurements}

Radiochemicals and RIAs for the analysis of leptin, ghrelin and cortisol were purchased from Mediagnost (Reutlingen, Germany), Phoenix (Belmont, California, USA), and DSL (Sinsheim, Germany). ELISA assays for the measurement of insulin and hGH were purchased from DSL.

All immunological systems have been evaluated in our laboratory, where insufficient data on pre-analytic influences on the assay were provided by the manufacturers (Gröschl et al. 2000, Gröschl et al. 2002). Sensitivities and intra-assay coefficients of variation of the assays were $32 \mathrm{ng} / 1$ for leptin $(7 \cdot 3 \%), 2 \mathrm{ng} / 1$ for ghrelin $(4 \cdot 0 \%)$, $3 \cdot 0 \mathrm{nmol} / 1$ for cortisol $(5 \cdot 2 \%), 0 \cdot 01 \mu \mathrm{g} / 1$ for hGH $(5 \cdot 3 \%)$ and $0 \cdot 26 \mathrm{IU} / 1$ for insulin $(6 \cdot 2 \%)$.

\section{Statistics and calculations}

Data are expressed as means \pm S.E.M., if not otherwise indicated. For graphical presentation, variations were expressed as percentages relative to the basal $\left(t_{0}\right)$ value rather than in concentrations. The area under curve (AUC) for serum concentration versus time for each AA and hormone was calculated using Prism software (GraphPad, San Diego, USA). Statistical analysis was performed using ANOVA with Bonferroni's $t$-test and differences were considered to be significant when $P<0 \cdot 05$. Linear regression analysis was performed for hormone values, percentual variations, and AUC results.

\section{Results}

Peak serum AA concentrations were reached at $30 \mathrm{~min}$ for Met and at $60 \mathrm{~min}$ for Val, Leu, Phe, Try, Lys, Thr and Ile (Fig. 1). For Tyr, peak serum values were reached at $150 \mathrm{~min}$ and for Cys at $180 \mathrm{~min}$. Serum concentrations increased, in relation to the $\mathrm{t}_{0}$ values, up to $353 \%$ for Ile, $301 \%$ for Val, 294\% for Met, 361\% for Leu, 262\% for Try, $274 \%$ for Lys, $225 \%$ for Thr and $221 \%$ for Phe $(P<0 \cdot 0001)$. The correlation between the dose and the AUC values for a particular AA was significant in most cases. Additionally, a significant correlation was found between the AUC values of Leu and Ile $\left(r^{2}=0.863\right.$, $P<0 \cdot 01)$, Met and Val $\left(\mathrm{r}^{2}=0 \cdot 870, P<0 \cdot 01\right)$, Met and Ile $\left(r^{2}=0 \cdot 799, P<0 \cdot 01\right)$, Leu and Val $\left(r^{2}=0 \cdot 725, P<0 \cdot 05\right)$, Met and Leu $\left(r^{2}=0.634, \quad P<0.05\right)$, Leu and Thr $\left(\mathrm{r}^{2}=0.634, \quad P<0.05\right)$ and Ile and Thr $\left(\mathrm{r}^{2}=0.571\right.$, $P<0 \cdot 05)$.

Interestingly Leu, with the highest concentration in the test mixture, did not show the highest serum concentration or greatest AUC value, nor did Try at the lowest concentration in the mixture show the flattest serum peak 


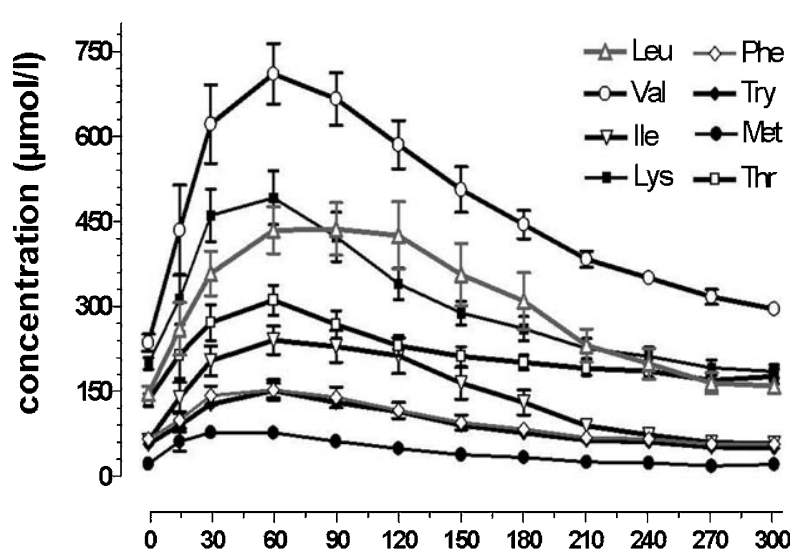

Figure 1 Serum kinetics of essential AA after oral ingestion, eight of the 11 components of the mixture shown as examples (mean \pm S.E.M.). Compared with $t_{0}$, values up to $353 \%$ for lle, $301 \%$ for Val, 294\% for Met, 361\% for Leu, 262\% for Try, 274\% for Lys, and $225 \%$ for Thr and $221 \%$ for Phe were reached $(P<0 \cdot 0001)$.

or smallest AUC value. In the iso-caloric control group, however, no changes in circulating AA could be observed, despite the fact that the milk proteins during digestion are also cleaved into lower molecular AA before gradual absorption through the gastric mucosa.

In all three groups serum levels for blood glucose remained constant throughout the study period. The individual mean values differed only slightly from $4 \cdot 96 \pm 0 \cdot 38 \mathrm{mmol} / 1$ to $5 \cdot 35 \pm 0.09 \mathrm{mmol} / 1$.

FFA (mmol/l) increased gradually irrespective of whether the volunteers ingested either AA (from $0.32 \pm 0.06$ to $0.61 \pm 0.10$, mean increase $215 \%$ ) or skimmed milk powder (from $0.32 \pm 0.08$ to $0.52 \pm 0.05$, mean increase $217 \%$ ) or remained fasted (from $0 \cdot 45 \pm 0 \cdot 1$ to $0.69 \pm 0.05$, mean increase $178 \%$ ). These changes were not significant in any of the groups $(P>0 \cdot 05)$.

Endocrine parameters showed diverse responses to the ingestion of the AA mixture. The most dramatic responses were found for insulin concentrations (Fig. 2). These increased significantly $(P<0.0001)$ within 20 min with an early return to basal values by $150 \mathrm{~min}$. Starting with basal values of $4.3 \pm 0.6 \mathrm{IU} / 1$ a sharply defined maximum of $19 \cdot 5 \pm 4 \mathrm{IU} / 1\left(500 \%\right.$ of $\left.\mathrm{t}_{0}\right)$ was reached. Immediately after this peak insulin values declined exponentially, reaching basal values at around $150 \mathrm{~min}$. From then on, insulin decreased further and reached final concentrations of $2 \cdot 7 \pm 0 \cdot 4 \mathrm{IU} / 1$, representing $32 \%$ of the initial values. In the iso-caloric controls, an identical pattern could be observed basal values of $4 \cdot 2 \pm 0 \cdot 6 \mathrm{IU} / 1$ rapidly increased to a peak at $t_{20}\left(14 \cdot 5 \pm 3 \mathrm{IU} / 1,400 \%\right.$ of $\left.t_{0}\right)$ followed by an exponential decline to basal values. This lowest point was reached earlier than in the AA group $\left(t_{90}\right)$. In fasting control subjects however, insulin remained unchanged throughout the entire study period.

Cortisol levels declined constantly $(P<0 \cdot 01)$ from $519 \pm 36 \mathrm{nmol} / 1$ beginning immediately after AA uptake

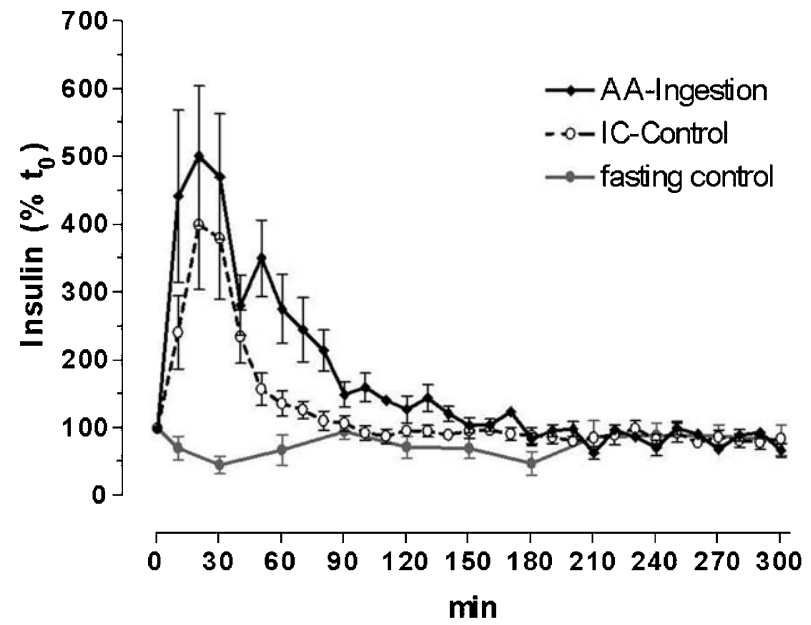

Figure 2 Serum insulin after ingestion of a single physiological dose of essential $A A \downarrow$, in the iso-caloric $\bigcirc$ and in the fasting control group $C$ compared with initial values in \%. Data are presented as mean \pm S.E.M. The increase in the AA and iso-caloric control group was significant $(P<0 \cdot 0001)$.

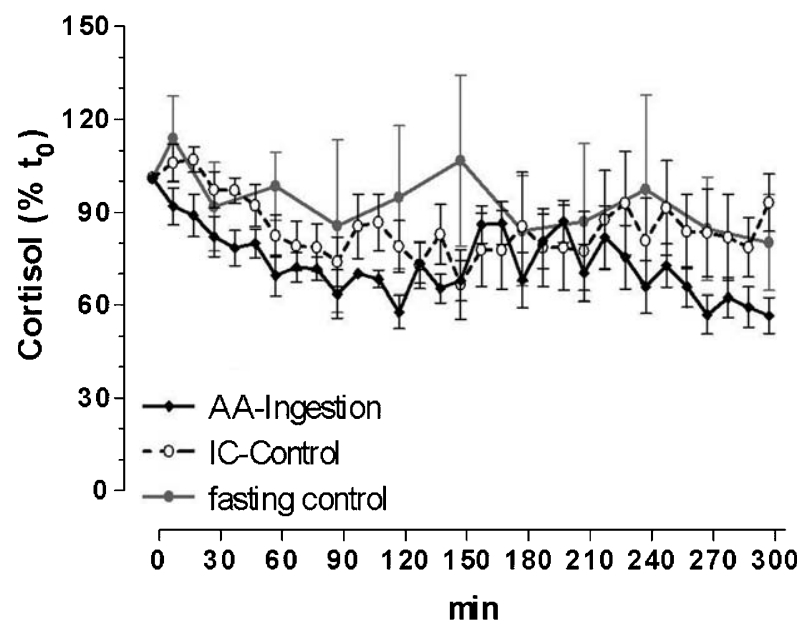

Figure 3 Serum cortisol after ingestion of a single physiological dose of essential AA $\downarrow$, in the iso-caloric $\bigcirc$ and in the fasting control group $\mathrm{C}$ compared with initial values in \%. Data are presented as mean \pm S.E.M. The decrease following AA ingestion was significant $(P<0 \cdot 01)$.

to $265 \pm 19 \mathrm{nmol} / \mathrm{l}\left(51 \%\right.$ of $\left.\mathrm{t}_{0}\right)$ at the end of the study. The course of cortisol in relation to basal values is shown in Fig. 3. Cortisol levels in both control groups also tended to decline during the study. This decline was not significant in fasting controls $(P>0 \cdot 05)$. In iso-caloric controls however, initial values $\left(t_{0}=326 \pm 30 \mathrm{nmol} / \mathrm{l}\right)$ were almost regained at the end of the study period $\left(\mathrm{t}_{300}=295 \pm 25 \mathrm{nmol} / \mathrm{l}\right)$ after an initial decline to $229 \pm 14 \mathrm{nmol} / 1\left(\mathrm{t}_{90}\right)$.

As with insulin, hGH was also dramatically affected by AA administration in all of our subjects. However, the 


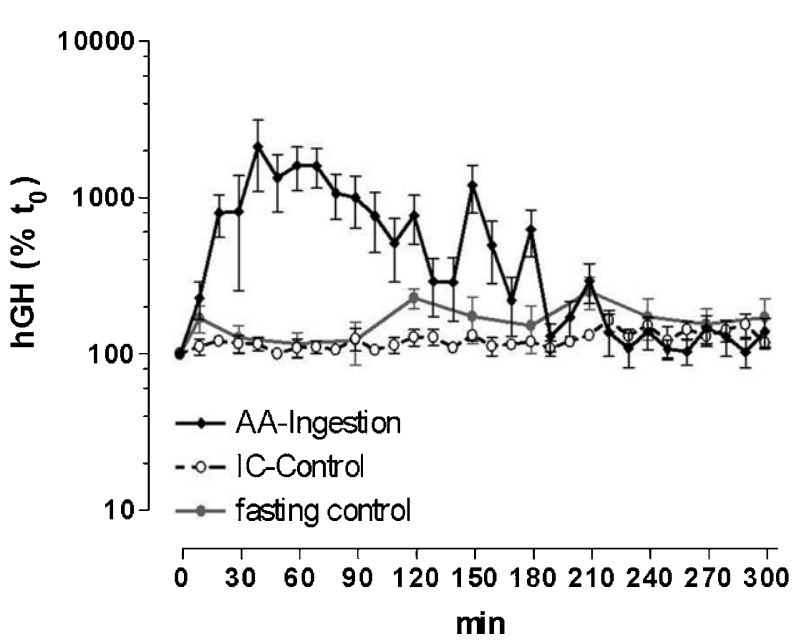

Figure 4 Course of hGH in serum after ingestion of a single physiological dose of essential AA the fasting control group $\bigcirc$ compared with initial values in percentages. Data are presented as means \pm S.E.M. Increases in the AA group were significant $(P<0 \cdot 0001)$. Please consider the $\log$ scale for this figure.

individual response was not as uniform, and the mean values formed a broad plateau-like peak (Fig. 4). The concentrations rose up to $5 \cdot 1 \pm 2 \cdot 2 \mu \mathrm{g} / 1(2100 \pm 1013 \%$ of $\left.\mathrm{t}_{0}\right)$ after $40 \mathrm{~min}(P<0 \cdot 0001)$ beginning with low basal values of $0 \cdot 3 \pm 0 \cdot 05 \mu \mathrm{g} / 1$. The results forming the plateau presented in Fig. 4 should be seen in a differentiated way. Only eight of the 13 volunteers showed a plateau in hGH concentrations lasting for a minimum of $30 \mathrm{~min}$; the remaining AA-subjects showed either one $(n=3)$ or two $(n=2)$ peaks at 60,150 , and/or $180 \mathrm{~min}$, respectively. In contrast, iso-caloric control subjects showed no significant alterations in the $\mathrm{hGH}$ values during the study, and in fasting subjects hGH levels tended to increase (not significant) towards the end of the study to up to $148 \pm 50 \%$ of the initial values.

The effects shown by leptin during the first hour of the study varied between groups (Fig. 5). In the AA group, a decline down to $60 \%$ of the $t_{0}$ values occurred. In contrast, the fasting controls showed leptin values increasing to up to $121 \%$ of the $t_{0}$ values. However, neither these temporal changes nor the changes during the entire study period for any of the three groups were significant.

Interesting changes were found for the gastric peptide hormone ghrelin. In the AA group concentrations increased slightly up until $t_{180}(P<0 \cdot 05)$. After that, a significant rise was observed until the end of the study period $(P<0 \cdot 001)$. The minimum ghrelin concentration $(286 \pm 39 \mathrm{ng} / \mathrm{l})$ was noted at the initial sampling. At the end of the study period, maximum values of $787 \pm 139 \mathrm{ng} / \mathrm{l}$ were found. This corresponds to a $2 \cdot 75-$ fold increase, as presented in Fig. 6. Interestingly, in fasting control subjects the increase of ghrelin was less marked $\left(t_{0}=181 \pm 23 \mathrm{ng} / 1\right.$ up to $t_{300}=299 \pm 63 \mathrm{ng} / 1,1 \cdot 7$-fold

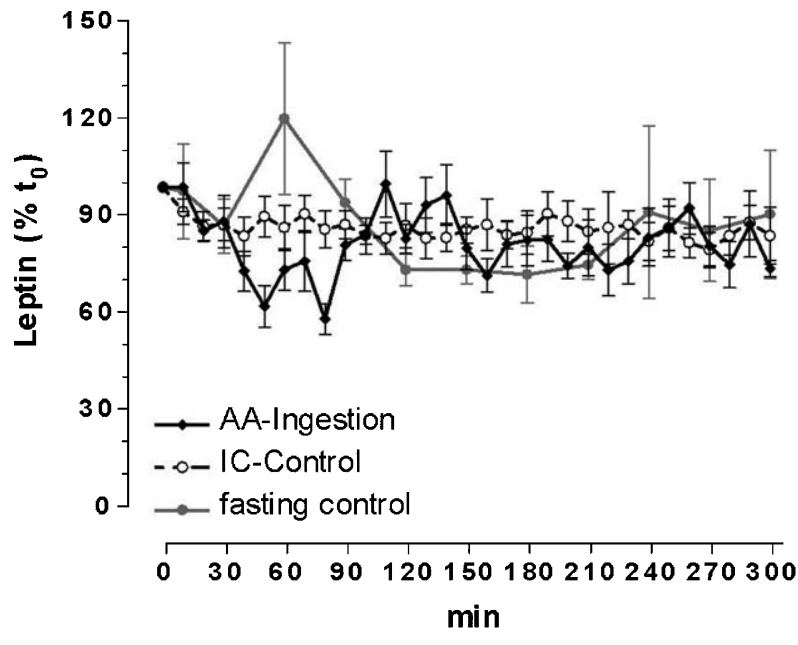

Figure 5 Serum leptin after ingestion of a single physiological dose of essential $\mathrm{AA} \diamond$, in the iso-caloric $\bigcirc$ and in the fasting control group $C$ compared with initial values an percentages. Data are presented as means \pm S.E.M.

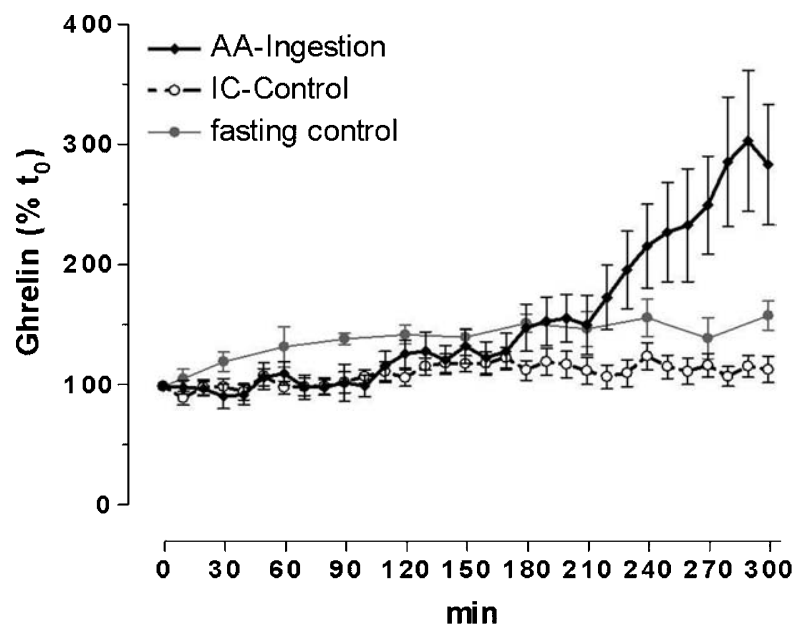

Figure 6 Serum ghrelin after ingestion of a single physiological dose of essential $A A \bullet$, in the iso-caloric $O$ and in the fasting control group $C$ compared with initial values an percentages. Data are presented as mean \pm S.E.M. Ghrelin levels differed significantly between the two groups from 240 min onwards $(P<0 \cdot 01)$.

increase) but still significant $(P<0 \cdot 05)$. In the iso-caloric controls, however, no significant changes were found at all. Starting with initial values of $188 \pm 16 \mathrm{ng} / \mathrm{l}$, values of $207 \pm 15 \mathrm{ng} / \mathrm{l}$ were found at the end of the study period.

Performing linear regression analysis, we could not find any significant correlation between either the hormone concentrations or the calculated percent changes in relation to the basal $t_{0}$ value. Interestingly, there was no significant correlation between the AUC values of the hormones after baseline correction. 

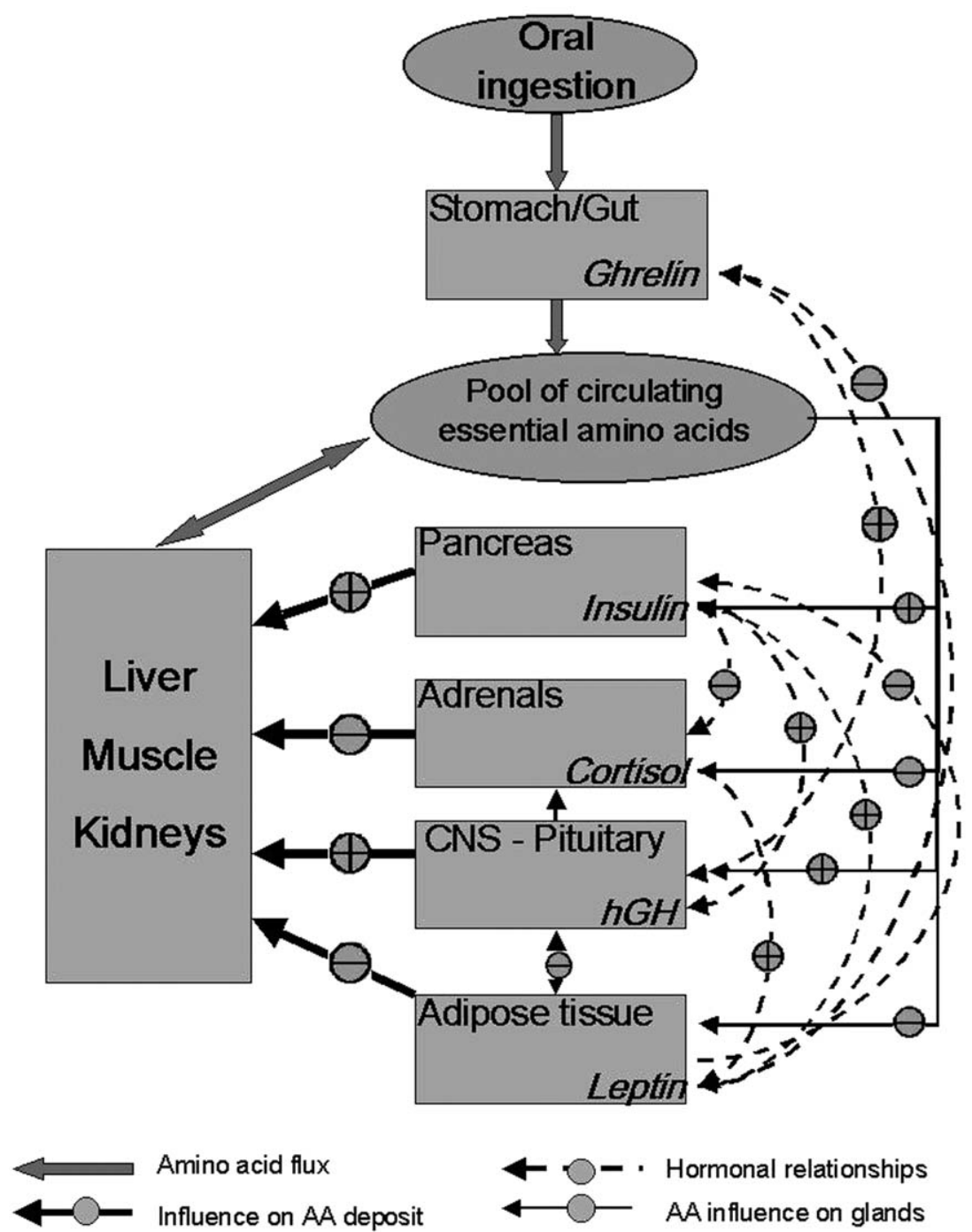

Figure 7 Simplified compartmental model of the endocrine responses to oral AA ingestion based on the findings of this study and data from the literature. Detailed explanation is provided in the discussion. Included are tissues with depository (muscle, liver, kidney), and endocrine (stomach, pancreas, adrenal glands, central nervous system, adipose tissue) function. Arrows symbolise interrelationships. +, positive regulation; -, negative regulation.

\section{Discussion}

In this study we investigated the simultaneous responses of a number of important metabolic hormones, including leptin and ghrelin, to a single oral bolus of essential AA. In order to differentiate whether the hormonal changes were anabolic or catabolic, we included two different control groups. One was iso-caloric in order to analyse the anabolic pathways, and one was fasted in order to resolve the catabolic pathways after AA ingestion. Furthermore, changes in glucose and FFA were documented. The comparison of these parameters, particularly in the AA group and the skimmed milk group, proves that the caloric load in these groups was in fact iso-caloric.

After oral ingestion and transport through the gastrointestinal epithelia the AA circulate within the bloodstream until transported into peripheral tissues. The intestinal uptake is mediated by several hormones, some of which we investigated in their time courses and interactions.

Based on the results of this study and data from the literature, we have summarised the hormonal responses to the ingestion of a physiological AA mixture in a simplified compartment model, presented in Fig. 7. 
In both the AA group and the iso-caloric controls, insulin was secreted rapidly within the first minute of the experiment reaching a maximum after $20 \mathrm{~min}$. Consequently, the organism reacts to ingestion by increasing the permeability of the cell membranes to valuable essential AA. It has been shown that insulin facilitates this uptake into different tissues rapidly after its release (Sugahara et al. 1987), as indicated in Fig. 7 (Prior \& Smith 1983). It is interesting to see that the effect of insulin is dose dependant (Tessari 1994) allowing individual clearance of serum AA according to the metabolic needs of the subject. It is notable that the insulin release after the intake of the milk powder solution mimics the course of the AA group. Caloric load, therefore, seems to be the main determinant for insulin secretion, rather than the composition of the ingested meal.

After a certain time delay after insulin release, hGH serum concentrations increased rapidly. It has been shown that the release of hGH by the pituitary is supported by the initial insulin peak (Muggeo et al. 1975), as has been considered in our model. In contrast to the insulin peak, which was very homogenous in the volunteers of the AA group, the hGH release showed a higher individual variability. This indicates that personal response may be based on factors such as age, individual food preferences or training status, as described by Chromiak \& Antonio (2002). However, a highly significant hGH release was observed in all of the members of the AA group, which correlated well with previously published data (Muggeo et al. 1975, Cameron et al. 1988, Lundeberg et al. 1991). This indicates a shift towards anabolic processes (Miers \& Barrett 1998) and is supported by the data from the control groups. No changes were found in the iso-caloric controls, but a slight, significant increase could be observed in the fasting group. In our view, this finding suggests that the insulin peak alone is not responsible for the hGH secretion. Possibly a supply of essential AA causes both insulin and hGH release, the latter of which is facilitated by the preceding insulin peak.

The significant decline of serum cortisol within $30 \mathrm{~min}$ after AA ingestion underlines the general view that AA also stimulate catabolic pathways (Chaussain et al. 1976, Kerr et al. 1978). This also explains the constancy of blood glucose levels. Glucocorticoids are responsible for the transcription and activation of gluconeogenetic enzymes (Khani \& Tayek 2001). It is possible that the supply of AA enables the organism to reduce this enzymatic activity until additional fuels are cleared from the serum. Moreover, this effect may also be mediated by insulin (Fig. 7), which acts antagonistically to cortisol (Louard et al. 1994). The negative influence of glucocorticoids on AA uptake by various tissues is also indicated in our model. The reduced serum cortisol found in the study would therefore be a prerequisite for an optimal AA uptake similar to the uptake of glucose into peripheral tissues (Munck 1971). This is supported by our finding that a slight, but insignificant decrease in cortisol levels was also observed in the iso-caloric control group.

Leptin, a peptide hormone produced primarily in adipocytes (Friedman \& Halaas 1998) and the gastrointestinal tract (Bado et al. 1998, Gröschl et al. 2001), is responsible for satiety and decreases food intake through its interaction with feeding centres in the hypothalamus (Schwartz 2001). This is indicated in our model by a negative interaction between adipose tissue and the CNS. Additionally, insulin up-regulates the release of leptin after food intake in healthy rodents and humans (Boden et al. 1997, Askari et al. 2000), as leptin causes a negative feedback in the pancreas (Ahren \& Havel 1999), as shown in Fig. 7. Furthermore leptin facilitates AA uptake by the activation of specific transporters, as reported for human placenta (Jansson et al. 2003).

In our study however, serum leptin did not change significantly. Slight but insignificant changes as observed during our study may also be based on the rhythmical secretion of this hormone (Nishiyama et al. 2000). This finding may indicate that a single physiological dose of AA is not a sufficient stimulus for a neuroendocrine response leading to significantly decreased leptin levels, despite the marked insulin secretion. Not only the supply of metabolic fuel but also mechanoreceptive stimuli in the stomach play an important role in inducing satiety. These stimuli are additionally responsible for an increased release of leptin (Gaige et al. 2002). The lack of gastric stimulation before and during the study may therefore explain the more or less constant leptin values. This may also explain why leptin levels remained unchanged in the iso-caloric control group. Surprisingly, leptin values remained constant in fasting controls too. In this group we expected decreasing values in response to hunger. Perhaps the constancy of glucose levels during the study inhibited a significant decrease of this peptide. Additionally it must be mentioned that leptin has been described as a rather long-term regulator of energy expenditure (Wilding 2002). Significant changes in leptin values after intake of AA or other kinds of food may therefore not occur within the $5 \mathrm{~h}$ of the present study.

Data from the literature indicate that there is a negative interrelation between hGH and leptin (Rauch et al. 1998), whereas glucocorticoids have a stimulatory effect on leptin release (Kiess et al. 1996, Trayhurn \& Rayner 1996). In our model, increased hGH and decreased cortisol levels after AA ingestion have an inhibiting effect on the synthesis of leptin.

This explanation is additionally supported by the continuously rising ghrelin levels in each of our subjects. This gastric peptide has been described as inducing hunger, driving the organism to increase food intake (Nakazato et al. 2001). The slight increase shown in the control subjects can be understood simply as a response to the fasting state. In contrast, the iso-caloric load in the control group ingesting milk powder seems to be sufficient to 
suppress this signal of starvation. Ghrelin also has a growth hormone releasing function (Date et al. 2000), which is further evidence for the induction of anabolic pathways by oral AA ingestion. This point is also considered in our model, although in our study no further hGH release was observed in response to the rising ghrelin levels. It is possible however, that the fasting state of the subjects lasting more than $12 \mathrm{~h}$ before starting the experiment, had already led to high ghrelin $t_{0}$ values, which then facilitated the hGH release after the AA uptake. Another possible explanation for this finding is that the strong stimulatory effect of ghrelin on the release of hGH may partially be equalised by the inhibitory influence of the slight, insignificant increase of FFA levels on hGH (Broglio et al. 2002). Furthermore, recently published data indicate that ghrelin release is not suppressed by insulin (Caixas et al. 2002); moreover insulin secretion seems to be additionally stimulated by ghrelin, as has been shown in rodents (Adeghate \& Ponery 2002).

The frequently described negative relationship between leptin and ghrelin (Bagnasco et al. 2002, Beck et al. 2002, Kalra et al. 2003) is considered in our model although we could not find any significant correlation of the hormone values measured. We would have expected at least a weak negative correlation between leptin and ghrelin, but this was absent due to the unexpected constancy of leptin. Other studies describe a rather strong negative correlation between the two hormones in study groups with a wide spread of body mass indices. A further explanation for the lack of correlation here could be our relatively homogeneous study group regarding fat content, age and health. These findings will be considered in further studies planned to investigate endocrine parameters in volunteers with more diverse auxological conditions.

In conclusion, this study provides data on the endocrine responses to a physiological dose of essential AA. In fact, it is the first study to consider the newly discovered peptides leptin and ghrelin and to show the course of the observed hormones in relation to each other. Further investigations with regard to other kinds of food supply are necessary for a better understanding of the relations of hormones in a metabolic context.

\section{Acknowledgements}

We are very grateful to the technical staff of the clinical chemical laboratory for their assistance, especially Mr. Norbert Meier. We also thank SHS International, Heilbronn, Germany, for the supply of E-AM powder.

\section{References}

Adeghate E \& Ponery AS 2002 Ghrelin stimulates insulin secretion from the pancreas of normal and diabetic rats. Journal of Neuroendocrinology 14 555-560.
Ahren B \& Havel PJ 1999 Leptin inhibits insulin secretion induced by cellular cAMP in a pancreatic B cell line (INS-1 cells). American Journal of Physiology 277 R959-R966.

Askari H, Liu J \& Dagogo-Jack S 2000 Hormonal regulation of human leptin in vivo: effects of hydrocortisone and insulin. International Journal of Obesity and Related Metabolic Disorders 24 1254-1259.

Bado A, Levasseur S, Attoub S, Kermorgant S, Laigneau JP, Bortoluzzi MN, Moizo L, Lehy T, Guerre Millo M, Le-Marchand Brustel Y et al. 1998 The stomach is a source of leptin. Nature 394 790-793.

Bagnasco M, Kalra PS \& Kalra SP 2002 Ghrelin and leptin pulse discharge in fed and fasted rats. Endocrinology 143 726-729.

Beck B, Musse N \& Stricker-Krongrad A 2002 Ghrelin, macronutrient intake and dietary preferences in long-evans rats. Biochemical and Biophysical Research Communications 292 1031-1035.

Boden G, Chen X, Kolaczynski JW \& Polansky M 1997 Effects of prolonged hyperinsulinemia on serum leptin in normal human subjects. Journal of Clinical Investigation 100 1107-1113.

Broglio F, Benso A, Gottero C, Prodam F, Grottoli S, Tassone F, Maccario M, Casanueva FF, Dieguez C, Deghenghi R et al. 2002 Effects of glucose, free fatty acids or arginine load on the GH-releasing activity of ghrelin in humans. Clinical Endocrinology 57 265-271.

Caixas A, Bashore C, Nash W, Pi-Sunyer F \& Laferrere B 2002 Insulin, unlike food intake, does not suppress ghrelin in human subjects. Journal of Clinical Endocrinology and Metabolism $\mathbf{8 7}$ 1902-1906.

Cameron CM, Kostyo JL, Adamafio NA, Brostedt P, Roos P, Skottner A, Forsman A, Fryklund L \& Skoog B 1988 The acute effects of growth hormone on amino acid transport and protein synthesis are due to its insulin-like action. Endocrinology 122 471-474.

Chaussain JL, Georges P, Olive G \& Job JC 1976 Effect of 24 hour fast in obese children. Biomedicine 25 299-302.

Chromiak JA \& Antonio J 2002 Use of amino acids as growth hormone-releasing agents by athletes. Nutrition 18 657-661.

Copeland KC \& Nair KS 1994 Acute growth hormone effects on amino acid and lipid metabolism. Journal of Clinical Endocrinology and Metabolism 78 1040-1047.

Dashman T \& Sansaricq C 1993 Nutrition in the management of inborn errors of metabolism. Clinics in Laboratory Medicine $\mathbf{1 3}$ 407-432.

Date Y, Murakami N, Kojima M, Kuroiwa T, Matsukura S, Kangawa K \& Nakazato M 2000 Central effects of a novel acylated peptide, ghrelin, on growth hormone release in rats. Biochemistry and Biophysics Research Communications 275 477-480.

de Precigout V, Chauveau P, Delclaux C, El-Haggan W, Baillet L, Barthe N, Gobinet A Combe C \& Aparicio M 2000 No change of hyperleptinemia despite a decrease in insulin concentration in patients with chronic renal failure on a supplemented very low protein diet. American Journal of Kidney Disease 36 1201-1206.

Drewes C, Nauck MA, Horn R, Holst J, Schmiegel W \& Brabant G 1997 A liquid mixed meal or exogenous glucagon-like peptide 1 (GLP-1) do not alter plasma leptin concentrations in healthy volunteers. Acta Diabetologica 34 230-234.

Friedman JM \& Halaas JL 1998 Leptin and the regulation of body weight in mammals. Nature 395 763-770.

Fukagawa NK, Minaker KL, Young VR \& Rowe JW 1986 Insulin dose-dependent reductions in plasma amino acids in man. American Journal of Physiology 250 E13-E17.

Gaige S, Abysique A \& Bouvier M 2002 Effects of leptin on cat intestinal vagal mechanoreceptors. Journal of Physiology 543 679-689.

Gröschl M, Wagner R, Dörr HG, Blum WF, Rascher W \& Dötsch J 2000 Variability of leptin values measured from different sample matrices. Hormone Research 54 26-31. 
Gröschl M, Rauh M, Wagner R, Neuhuber W, Metzler M, Tamgüney G, Zenk J, Schoof E, Dörr HG, Blum WF et al. 2001 Identification of leptin in human saliva. Journal of Clinical Endocrinology and Metabolism 86 5234-5239.

Gröschl M, Wagner R, Dötsch J, Rascher W \& Rauh M 2002 Pre-analytical influences on the measurement of ghrelin. Clinical Chemistry 48 1114-1116.

Jansson N, Greenwood SL, Johansson BR, Powell TL \& Jansson T 2003 Leptin stimulates the activity of the system A amino acid transporter in human placental villous fragments. Journal of Clinical Endocrinology and Metabolism 88 1205-1211.

Kalra SP, Bagnasco M, Otukonyong EE, Dube MG \& Kalra PS 2003 Rhythmic, reciprocal ghrelin and leptin signaling: new insight in the development of obesity Regulatory Peptides 111 1-11.

Kerr DS, Stevens MC \& Robinson HM 1978 Fasting metabolism in infants I: effect of severe undernutrition on energy and protein utilization Metabolism 27 411-435.

Khani S \& Tayek JA 2001 Cortisol increases gluconeogenesis in humans: its role in the metabolic syndrome. Clinical Science 101 739-747.

Kiess W, Englaro P, Hanitsch S, Rascher W, Attanasio A \& Blum WF 1996 High leptin concentrations in serum of very obese children are further stimulated by dexamethasone. Hormone and Metabolism Research 28 708-710.

Kingston WJ, Moxley RT \& Griggs RC 1986 Effect of testosterone on whole body amino acid utilization in myotonic dystrophy. Metabolism 35 928-932.

Levy HL 1989 Nutritional therapy for selected inborn errors of metabolism. Journal of the American College of Nutrition 8 S54-S60.

Liao K \& Lane MD 1995 Expression of a novel insulin-activated amino acid transporter gene during differentiation of 3T3-L1 preadipocytes into adipocytes. Biochemistry and Biophysics Research Communications 208 1008-1015.

Louard RJ, Bhushan R, Gelfand RA, Barrett EJ \& Sherwin RS 1994 Glucocorticoids antagonize insulin's antiproteolytic action on skeletal muscle in humans. Journal of Clinical Endocrinology and Metabolism 79 278-284.

Lundeberg S, Belfrage M, Wernerman J, von-der-Decken A, Thunell S \& Vinnars E 1991 Growth hormone improves muscle protein metabolism and whole body nitrogen economy in man during a hyponitrogenous diet. Metabolism 40 315-322.

Miers WR \& Barrett EJ 1998 The role of insulin and other hormones in the regulation of amino acid and protein metabolism in humans. Journal of Basic and Clinical Physiology and Pharmacology 9 235-253.

Muggeo M, Tiengo A, Fedele D \& Crepaldi G 1975 The influence of plasma triglycerides on human growth hormone response to arginine and insulin: a study in hyperlipemics and normal subjects. Hormone and Metabolism Research 7 367-374.
Munck A 1971 Glucocorticoid inhibition of glucose uptake by peripheral tissues: old and new evidence, molecular mechanisms, and physiological significance. Perspectives in Biology and Medicine 14 265-269.

Nagata Y, Homma H, Lee JA \& Imai K 1999 D-Aspartate stimulation of testosterone synthesis in rat Leydig cells. FEBS Letters $\mathbf{4 4 4}$ 160-164.

Nakazato M, Murakami N, Date Y, Kojima M, Matsuo H, Kangawa K \& Matsukura S 2001 A role for ghrelin in the central regulation of feeding. Nature 409 194-198.

Nishiyama M, Makino S, Suemaru S, Nanamiya W, Asaba K, Kaneda T, Mimoto T, Nishioka T, Takao T \& Hashimoto K 2000 Glucocorticoid effects on the diurnal rhythm of circulating leptin levels. Hormone Research 54 69-73.

Prior RL \& Smith SB 1983 Role of insulin in regulating amino acid metabolism in normal and alloxan-diabetic cattle. Journal of Nutrition 113 1016-1031.

Rauch F, Westermann F, Englaro P, Blum WF \& Schonau E 1998 Serum leptin is suppressed by growth hormone therapy in growth hormone-deficient children. Hormone Research 50 18-21.

Rubinstein ML \& Federman DG 2000 Sports supplements: can dietary additives boost athletic performance and potential? Postgraduate Medicine 108 103-112.

Santora AC, Wheeler FB, DeHaan RL \& Elsas LJ 1979 Relationship of insulin binding to amino acid transport by cultured 14-day embryonic chick heart cells. Endocrinology 104 1059-1068.

Schwartz MW 2001 Brain pathways controlling food intake and body weight. Experimental Biology Medicine 226 978-981.

Sugahara K, Voelker DR \& Mason RJ 1987 Insulin stimulates amino acid transport by alveolar type II epithelial cells in primary culture American Review of Respiratory Disease 135 617-621.

Tayek JA \& Katz J 1997 Glucose production, recycling, Cori cycle, and gluconeogenesis in humans: relationship to serum cortisol American Journal of Physiology 272 E476-E484.

Tessari P 1994 Effects of insulin on whole-body and regional amino acid metabolism. Diabetes and Metabolism Review 10 253-285.

Trayhurn P \& Rayner DV 1996 Hormones and the ob gene product (leptin) in the control of energy balance. Biochemical Society Transmissions 24 565-570.

Wilding JP 2002 Neuropeptides and appetite control. Diabetic Medicine 8 619-627.

Received in final form 24 July 2003

Accepted 24 July 2003 